\title{
Association of the Parathyroid Adenoma Volume and the Biochemical Parameters in Primary Hyperparathyroidism (Endocrinol Metab 26:62-66, 2011, Yul Hwang-Bo et al.)
}

\section{Yul Hwang-Bo, Chan Soo Shin}

Department of Internal Medicine, Seoul National University College of Medicine, Seoul, Korea

본 논문에 대해 관심을 갖고 투고해주심에 감사 드립니다.

본 연구에서 부갑상선 선종의 낭종성 변화는 병리조직의 육안소 견에서 낭종이 관찰된 모든 경우를 포함하였습니다. 부갑상선 선종 의 낭종성 병변은 다양한 모양으로 나타날 수 있으며 그 모양에 따 라서 여러 기전으로 설명되고 있습니다[1,2]. 제3 또는 제 4 새열낭에 의해서 형성될 수 있으며 선종 내에 콜로이드 분비로 인해 큰 낭종 이 만들어 질 수도 있습니다. 또한 부갑상선 선종 실질내의 변질에 의해도 생길 수 있습니다. 본 연구에서 5 명의 환자가 부갑상선 선종 에 낭종성 변화를 보였고 선종 대부분을 차지하는 단일 낭종 뿐 아 니라 여러 개의 낭종을 포함하는 경우도 있었습니다. 낭종성 변화가 그 크기와 성상에 따라 차이가 있을 수 있으나 본 연구에서는 낭종 이 선종 실질 내에 공간을 형성한다는 점에서 낭종이 있는 경우는 모두 낭종성 변화가 있다고 정의하였습니다.

부갑상선 기능항진증 환자에서 수술 전 선종의 위치를 결정하기 위해서 Tc-99m MIBI를 이용한 부갑상선 스캔검사, 초음파, CT 등 다양한 검사방법이 이용되고 있습니다[3]. 그러나 어떤 검사가 더 우 월한지, 부가적인 검사가 선종의 위치 결정에 추가 이득이 있는지는 여전히 논란이 있습니다[4,5]. 본 연구에서는 선종의 위치를 결정하 기 위한 검사가 임상의의 판단에 의해 이루어졌고 초음파 검사나 CT 검사가 모든 환자에게 일괄적으로 시행되지는 않았습니다. 따라 서 수술 전 측정한 선종의 크기와 생화학적 지표들간의 연관성을 분석하기에는 한계가 있었습니다.

마지막으로 본 연구에서 부갑상선 선종의 크기와 혈청 인산의 사 이에 상관관계가 보였고 이러한 관찰은 선종의 크기 또는 무게를 생 화학적 지표들과 비교한 대부분의 연구와는 상반되는 결과였습니 다[6-8]. 그러나 Mózes 등[9]이 시행한 부갑상선 선종의 무게와 생화 학적 지표와의 연구에서는 본 연구와 다소 비슷한 결과를 보여주었 습니다. 따라서 본 연구를 포함하여 현재까지의 연구들은 대상수가 적으며 그 결과도 일관되지 않았습니다. 이러한 결과에는 각 연구에 포함된 환자 군의 신장기능, 단일 선종 여부, 선종의 병리학적 차이
등이 영향을 주었으리라고 사료됩니다.

본 연구를 결과를 토대로 생각하였을 때, 부갑상선 기능항진증에 서 선종의 크기 또는 무게와 생화학적 지표들간의 상관관계를 명확 하게 밝히기 위해서는 선종의 병리를 고려하여 많은 환자들을 대상 으로 한 연구가 필요할 것으로 사료됩니다.

\section{참고문헌}

1. Safran D: Functioning parathyroid cyst. South Med J 91:978-980, 1998

2. Fortson JK, Patel VG, Henderson VJ: Parathyroid cysts: a case report and review of the literature. Laryngoscope 111:1726-1728, 2001

3. Mariani G, Gulec SA, Rubello D, Boni G, Puccini M, Pelizzo MR, Manca G, Casara D, Sotti G, Erba P, Volterrani D, Giuliano AE: Preoperative localization and radioguided parathyroid surgery. J Nucl Med 44:14431458,2003

4. Moure D, Larranaga E, Dominguez-Gadea L, Luque-Ramirez M, Nattero L, Gomez-Pan A, Marazuela M: 99MTc-sestamibi as sole technique in selection of primary hyperparathyroidism patients for unilateral neck exploration. Surgery 144:454-459, 2008

5. Sukan A, Reyhan M, Aydin M, Yapar AF, Sert Y, Canpolat T, Aktas A: Preoperative evaluation of hyperparathyroidism: the role of dual-phase parathyroid scintigraphy and ultrasound imaging. Ann Nucl Med 22:123131,2008

6. Wagner PK, Rothmund M: [Correlation of tumor weight and typical pathologic laboratory parameters in primary and secondary hyperparathyroidism]. Langenbecks Arch Chir 360:133-139, 1983

7. Bindlish V, Freeman JL, Witterick IJ, Asa SL: Correlation of biochemical parameters with single parathyroid adenoma weight and volume. Head Neck 24:1000-1003, 2002

8. Hamidi S, Aslani A, Nakhjavani M, Pajouhi M, Hedayat A, Kamalian N: Are biochemical values predictive of adenoma's weight in primary hyperparathyroidism? ANZ J Surg 76:882-885, 2006

9. Mózes G, Curlee KJ, Rowland CM, van Heerden JA, Thompson GB, Grant CS, Farley DR: The predictive value of laboratory findings in patients with primary hyperparathyroidism. J Am Coll Surg 194:126-130, 2002 